\title{
Function of SLC7A7 in T-Cell Acute Lymphoblastic Leukemia
}

\author{
Xiaohui Jia,b Xiaoyun Yang ${ }^{a, b} \quad$ Nan Wanga,b Meiyun Kanga,b Yaping Wang ${ }^{a, b}$ \\ Liucheng Ronga,b Yongjun Fang ${ }^{a, b}$ Yao Xue $e^{a, b}$ \\ aDepartment of Hematology and Oncology, Children's Hospital of Nanjing Medical University, Nanjing, \\ ${ }^{b} K e y$ Laboratory of Hematology, Nanjing Medical University, Nanjing, China
}

\section{Key Words}

T-cell acute lymphoblastic leukemia (T-ALL) - SLC7A7 (Y+LAT1) - Transmembrane family • Amino acids $•$ Arginine

\begin{abstract}
Background/Aims: $\mathrm{Y}+\mathrm{LAT1}$ protein, encoded by the SLC7A7 gene (a member of the SLC7 family), forms the cationic amino acid transport system $y+L($ system $y+L$ ). This system transports cationic amino acids such as arginine and lysine out of the cell. Arginine, in particular, is critical for T-cell activation and function in the immune response. Methods: We analyzed the role of the SLC7A7 gene in the cellular activities of Jurkat cells, specifically the cell cycle and cell proliferation, apoptosis, migration, and invasion. Cell proliferation was assessed using the Cell Counting Kit-8. Apoptosis and the cell cycle were determined with a FACSCalibur flow cytometer. A Transwell chamber was used to measure cell invasion and migration. Results: The proliferative ability of Jurkat cells was not significantly altered by transfection with SLC7A7 overexpression vectors. However, SLC7A7 overexpression significantly decreased the percentage of apoptotic Jurkat cells $(P=0.007)$ but significantly increased the proportion of G1 phase cells $(P=0.029)$ and cell migration $(P<0.001)$ and invasion $(P<0.001)$. Knockdown of SLC7A7 increased the cell apoptosis rate $(P=0.006)$ but decreased the $G 1$ phase ratio $(P=$ $0.002)$ and cell migration $(P<0.001)$ and invasion $(P<0.001)$. Conclusions: SLC7A7 plays a significant role in the pathogenesis of T-cell acute lymphoblastic leukemia.
\end{abstract}

\section{Introduction}

Acute lymphoblastic leukemia (ALL) accounts for $25 \%$ of malignant tumors in children and is the most common childhood tumor [1-3]. Many factors contribute to its development [4-6], including abnormal gene expression, the high energy consumption of tumor cells, and, most importantly, the high expression of cell membrane transporters, which can affect tumor cell growth [7].

X. Ji, X. Yang and N. Wang contributed equally to this work.

\begin{tabular}{ll}
\hline Yongjun Fang & Dept. of Hematology and Oncology, Children's Hosp. of Nanjing Med. Univ. \\
and Yao Xue & Key Lab. of Hematology, Nanjing Med. Univ., No. 72 Guangzhou Road, Nanjing 210008 (China) \\
& Tel. 86-25-83117508, Fax 86-25-83304239, E-Mail dryjfang@gmail.com, yaoyao82986@126.com
\end{tabular}




\section{Cellular Physiology Cell Physiol Biochem 2018;48:731-740 \begin{tabular}{l|l} 
and Biochemistry Published online: July 19, 2018 & $\begin{array}{l}\text { D } 2018 \text { The Author(s). Published by S. Karger AG, Basel } \\
\text { www.karger.com/cpb }\end{array}$ \\
\hline
\end{tabular} Ji et al.: Function of SLC7A7 in T-ALL}

Amino acid transporters can be divided into two families: SLC3 and SLC7. The SLC7A7 (a member of the SLC7 family) gene encodes $\mathrm{y}^{+} \mathrm{LAT} 1$ protein, which is combined with the 4F2hc protein encoded by SLC3A2 to form the cationic amino acid transport system $\mathrm{y}^{+} \mathrm{L}$ (system $\left.\mathrm{y}^{+} \mathrm{L}\right)[8,9]$. This transport system exports cationic amino acids such as arginine and lysine out of the cell while importing a large neutral amino acid and a $\mathrm{Na}^{+}$ion into the cell [10-12]. The role of SLC7A7 in lysinuric protein intolerance has been extensively studied [8-12]. In addition, mutations in SLC7A7 causing cation transporter dysfunction are associated with a variety of clinical symptoms, such as high blood ammonia, renal dysfunction, gastrointestinal symptoms and abnormal hematopoiesis, growth retardation, osteoporosis, and pulmonary symptoms [13]. High expression of SLC7A7 is related to the prognosis of malignant glioma [14] and multiple myeloma [15] and drug resistance in ovarian cancer [16]. Moreover, the high expression of SLC7A7 is also associated with the radiotherapy sensitivity of lung cancer [17]. Barilli et al. found an increase in the mRNA expression of the SLC7A7 gene in human monocytes during the differentiation process of macrophages [18]. However, because the importance of SLC7A7 remains unknown in acute lymphocytic leukemia, we aimed to shed some light on the role of SLC7A7 in the pathogenesis, drug resistance, and prognosis of T-cell acute lymphocytic leukemia.

\section{Materials and Methods}

\section{Clinical samples}

This study was approved by the Ethics Committee of the Children's Hospital of Nanjing Medical University, and all participants' guardians provided signed informed consent for participation. Bone marrow samples were obtained from 17 T-ALL children and 19 children with immune thrombocytopenia at the initial diagnosis. The cases and controls ranged in age from 1 to 18 years old. All cases and controls were recruited from the Children's Hospital of Nanjing Medical University in an ongoing study starting in October 2015. All cases were diagnosed by morphology, immunology, cytogenetics, and molecular biology (MICM). Controls were recruited from the same geographical area, were age-, sex-, and frequency-matched to the cases, and were diagnosed with immune thrombocytopenia.

Cells

Jurkat cells (derived from a 14-year-old T-cell lymphoblastic leukemia patient) were obtained from the Chinese Center for Type Cultures Collections (CCTCC, China). The Jurkat T lymphocytes were cultured in $37^{\circ} \mathrm{C}$ with $5 \% \mathrm{CO}_{2}$ in a humidified incubator and maintained in RPMI-1640 medium supplemented with $10 \%$ fetal bovine serum (FBS) and 1\% penicillin/streptomycin.

\section{Reagents}

Lentivirus expressing short hairpin RNA (shRNA) targeting the SLC7A7 gene sequence and a negative control were purchased from GenePharma Co., Ltd. (Shanghai, China). Lentivirus expressing SLC7A7 and a negative control were purchased from Shanghai Hanheng Co., Ltd. (Shanghai, China). The SLC7A7 antibody was from Novus Biologicals (Abnova, Taipei, Taiwan). The $\beta$-actin antibody was from Santa Cruz Biotechnology, Inc. (Dallas, TX). Cell proliferation was measured using a Cell Counting Kit-8 (Dojindo, Kumamoto, Japan). A cell cycle detection kit (Keygen Biotech, Nanjing, China) was used to analyze the cell cycle. The apoptosis assay was performed using a PE Annexin V Apoptosis Detection Kit (BD Biosciences, Franklin Lakes, NJ). Transwell chamber slides were purchased from Merck Millipore (Burlington, MA). Fibronectin and Matrigel were purchased from Corning Inc. (Corning, NY). SYBR Green Master Mixture was purchased from Takara Bio Inc. (Otsu, Japan). The enzyme-linked immunosorbent assay (ELISA) kit used to analyze the supernatant content of arginine in transfected cells was purchased from Shanghai Jianglai Industrial (Shanghai, China).

Transfection

When the Jurkat cells reached $50 \%$ confluence, they were transfected with lentiviral vector or negative control virus (MOI = 100), and cultured at $37^{\circ} \mathrm{C}$ and $5 \% \mathrm{CO}_{2}$. The clone transfected with Lv-shSLC7A7 was 


\section{Cellular Physiology Cell Physiol Biochem 2018;48:731-740 \begin{tabular}{l|l} 
and Biochemistry Published online: July 19, 2018 & $\begin{array}{l}\text { D } 2018 \text { The Author(s). Published by S. Karger AG, Basel } \\
\text { www.karger.com/cpb }\end{array}$
\end{tabular} \\ Ji et al.: Function of SLC7A7 in T-ALL}

defined as the Lv-shSLC7A7 group, and cells transfected with negative control vectors were named the negative control group (NC). The clone transfected with Lv-SLC7A7 was defined as the Lv-SLC7A7 group, and cells transfected with negative control vectors were used as the control group (C). After transfection, puromycin was used to select cells for 2 weeks. The ability of the Lv-shRNA-SLC7A7 vectors to knockdown SLC7A7 and that of Lv-SLC7A7 vectors to overexpress SLC7A7 were investigated using quantitative realtime PCR (qRT-PCR) and western blotting.

\section{qRT-PCR}

Total RNA was prepared from cell lines using TRIzol reagent (Takara Biotechnologies (Dalian) Co., Ltd., Dalian, China) according to the manufacturer's protocol. For reverse transcription, double-stranded cDNA was synthesized from $500 \mathrm{ng}$ of total RNA using PrimeScript ${ }^{\mathrm{TM}}$ RT Master Mix (Takara Bio Inc.). qRT-PCR was performed with SYBR Green PCR Master Mix. The primer sequences were as follows (5'3'): SLC7A7 forward, CTCACTGCTTAACGGCGTGT; SLC7A7 reverse, CCAGTTCCGCATAACAAAGG; $\beta$-actin forward, 5'-TCACCCACACTGTGCCCATCTACGA-3'; $\beta$-actin reverse, 5'-CAGCGGAACCGCTCATTGCCAATGG-3'. The relative expression was calculated by the $2-\Delta \Delta \mathrm{Ct}$ method.

\section{Western blotting}

Cells exposed to different treatments were collected. The cell lysate was separated by $10 \%$ sodium dodecyl sulfate-polyacrylamide gel electrophoresis and proteins were transferred to polyvinylidene fluoride membrane (Millipore). The membrane was blocked with 5\% non-fat milk and then incubated with the primary antibodies overnight at $4{ }^{\circ} \mathrm{C}$ at a dilution of $1: 1,000$. After being rinsed, the membranes were incubated for $1 \mathrm{~h}$ at room temperature with secondary antibodies at a dilution of 1:1, 000. The membrane was then washed with TBST. Finally, immunoreactive protein bands were detected by the Molecular Imager ChemiDoc XRS+ System (Bio-Rad, Hercules, CA).

\section{Cell proliferation}

Jurkat cells exposed to different treatments were seeded in 96-well plates and cultured for 0, 24, 48, or $72 \mathrm{~h}$. Cell viability was assessed using the Cell Counting Kit-8. CCK-8 solution $(10 \mu \mathrm{L})$ was added to each well. After $2 \mathrm{~h}$, the optical density (OD) value of each well was recorded at a wavelength of $450 \mathrm{~nm}$. Cell viabilities with different treatments were calculated.

\section{Cell cycle assay}

Cells exposed to different treatments were fixed overnight with 75\% cold ethanol. After being washed twice with PBS, the cells were stained with propidium iodide and RNase A according to the manufacturer's protocol. The DNA content of the cells was determined with a FACSCalibur flow cytometer (BectonDickinson, Sparks, MD). After being stained, the cells were kept in the dark until analysis.

\section{Cell apoptosis assay}

Cells exposed to different treatments were washed with PBS and stained with PE and 7-AAD for 15 min according to the manufacturer's protocol. After the staining, the cells were analyzed within $1 \mathrm{~h}$. Apoptotic cells were detected by a FACSCalibur flow cytometer (Becton-Dickinson).

\section{Cell migration and invasion}

A Transwell chamber was used to measure cell invasion and migration. The day before the assay, fibronectin was placed on the bottom of the upper chamber. For the determination of Jurkat T-ALL cell migration, Transwell chambers were placed into 24-well plates; for the determination of Jurkat T-ALL cell invasion, 24-well plates were coated with $100 \mu \mathrm{L}$ Matrigel (Invitrogen, Shanghai, China) and then incubated at $37^{\circ} \mathrm{C}$ for $2 \mathrm{~h}$. In Transwell assays, Jurkat cells were seeded in upper chambers at a density of $2 \times 10^{5}$ cells/ well after treatment and were again suspended in RPMI 1640 medium. At the same time, $600 \mu \mathrm{L}$ of $10 \%$ FBS-1640 was added to the lower chamber. After $24 \mathrm{~h}$, migrated or invading Jurkat cells were fixed in $100 \%$ methanol for $30 \mathrm{~min}$. Cotton swabs were then used to remove non-migrated or non-invading Jurkat cells. Next, cells on the bottom surface of the membrane were stained with crystal violet for $20 \mathrm{~min}$. The numbers of migrated or invading cells were counted in five random fields under 200× magnification on an Olympus BX51 microscope (Olympus, Tokyo, Japan). Each experiment was independently repeated three times. 


\section{Cellular Physiology Cell Physiol Biochem 2018;48:731-740 and Biochemistry Published online: July 19, $2018 \quad \begin{aligned} & \text { DOI: } 2018 \text { The Author(s). Published by S. Karger AG, Basel } \\ & \text { www.karger.com/cpb }\end{aligned}$ \\ Ji et al.: Function of SLC7A7 in T-ALL}

\section{Arginine quantification}

The supernatants of transfected cells were collected (via centrifugation at $1000 \times g$ for $20 \mathrm{~min}$ ). We added $50 \mu \mathrm{L} /$ well of each standard solution and cell samples to the plate. Then, $100 \mu \mathrm{L} /$ well of HRPConjugate Reagent was added to the plate. The plate was sealed with a plate sealer and incubated at $37^{\circ} \mathrm{C}$ for $1 \mathrm{~h}$. The solution was discarded from the detection plate and the wells were briefly washed five times with $350 \mu \mathrm{L}$ wash buffer/well. Chromogen Solution A and Chromogen B were added to each well and the plate was incubated at $37^{\circ} \mathrm{C}$ for $15 \mathrm{~min}$. The color development was stopped by the addition of $50 \mu \mathrm{L}$ of Stop Solution to each well, which changes the blue color to yellow. Absorbance was read at $450 \mathrm{~nm}$ on a plate reader.

\section{Statistical analysis}

All data represent at least three independent experiments and are expressed as the mean \pm standard deviation. A Student's t-test or one-way analysis of variance test was used to compare differences between groups. Statistical analyses were carried out using Statistics Analysis System software (version 9.2; SAS Institute, Cary, NC). $P<0.05$ was considered statistically significant.

\section{Results}

Expression of SLC7A7 in the bone marrow samples of children

qRT-PCR was used to detect SLC7A7 expression in bone marrow samples. Compared with bone marrow samples from controls, the expression of SLC7A7 was higher in the bone marrow samples of children with T-ALL $(P=0.0221$; Fig. 1$)$, indicating a potential role for SLC7A7 in T-ALL development.

\section{Effects of SLC7A7 on Jurkat cell proliferation and apoptosis and} the cell cycle

Compared with the control group, the expression of SLC7A7 was downregulated in the Lv-shSLC7A7 group $(P=0.002)$ and upregulated in the Lv-SLC7A7 group ( $P=0.002$; Fig. 2).

As shown in Fig. 3, the proliferative ability of Jurkat cells transfected with Lv-shSLC7A7 was not different from that of cells transfected with sh-NC $(P=0.119$ for $0 \mathrm{~h}, P=0.127$ for $24 \mathrm{~h}, P=$ 0.199 for $48 \mathrm{~h}, P=0.094$ for $72 \mathrm{~h}$ ). In addition, the proliferative ability of Lv-SLC7A7-transfected cells was not different from that of control cells $(P=0.523$ for $0 \mathrm{~h}, P=0.789$ for $24 \mathrm{~h}, P=0.297$ for $48 \mathrm{~h}, P=0.072$ for $72 \mathrm{~h}$ ). Thus, SLC7A7 may not have a clear effect on Jurkat cell proliferation.

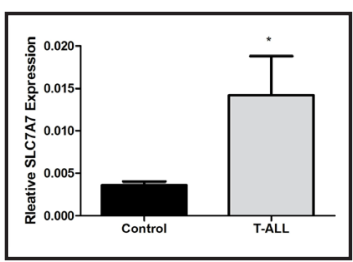

Fig. 1. Relative SLC7A7 expression in the bone marrow samples of controls and patients with T-ALL. *P $=0.022$. T-ALL, T-cell acute lymphoblastic leukemia.
Fig. 2. Effects of SLC7A7 knockdown and overexpression on SLC7A7 mRNA and protein levels. shRNA lentivirus for the SLC7A7 gene and SLC7A7-overexpressing viral vector were constructed to separately infect Jurkat cells. After the transfection, the cells were treated with puromycin for $48 \mathrm{~h}$. Interference efficiency was confirmed by real-time PCR and western blot. (A) mRNA expression of SLC7A7 in the control and Lv-shSLC7A7 groups $(\mathrm{P}=0.002)$. (B) Protein expression of SLC7A7 and mTOR in the control and Lv-shSLC7A7 groups. (C) mRNA expression of SLC7A7 in the control and SLC7A7 overexpression groups $(\mathrm{P}=0.002)$. (D) Protein expression of SLC7A7 and mTOR in the control and SLC7A7 overexpression groups.

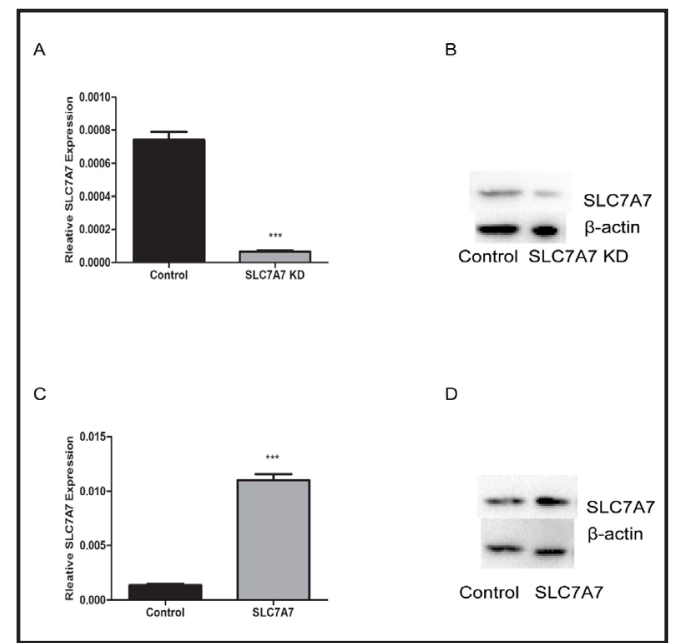


Fig. 3. Proliferation rates of Jurkat cells exposed to different treatments. (A) Cell proliferation rates in the control and LV-shSLC7A7 groups $(\mathrm{P}=0.119$ for $0 \mathrm{~h}, \mathrm{P}=0.127$ for $24 \mathrm{~h}, \mathrm{P}=0.199$ for $48 \mathrm{~h}, \mathrm{P}=0.094$ for $72 \mathrm{~h}$ ). (B) Cell proliferation rates in the control and Lv-SLC7A7 groups $(\mathrm{P}=$ 0.523 for $0 \mathrm{~h}, \mathrm{P}=0.789$ for $24 \mathrm{~h}, \mathrm{P}=0.297$ for $48 \mathrm{~h}, \mathrm{P}=$

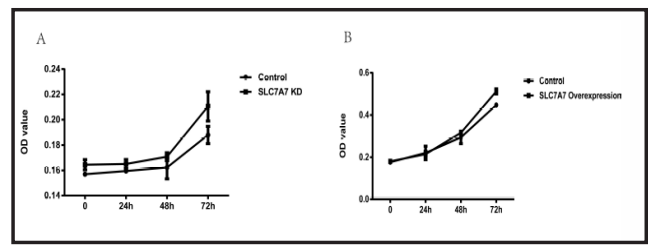
0.072 for $72 \mathrm{~h}$ ).

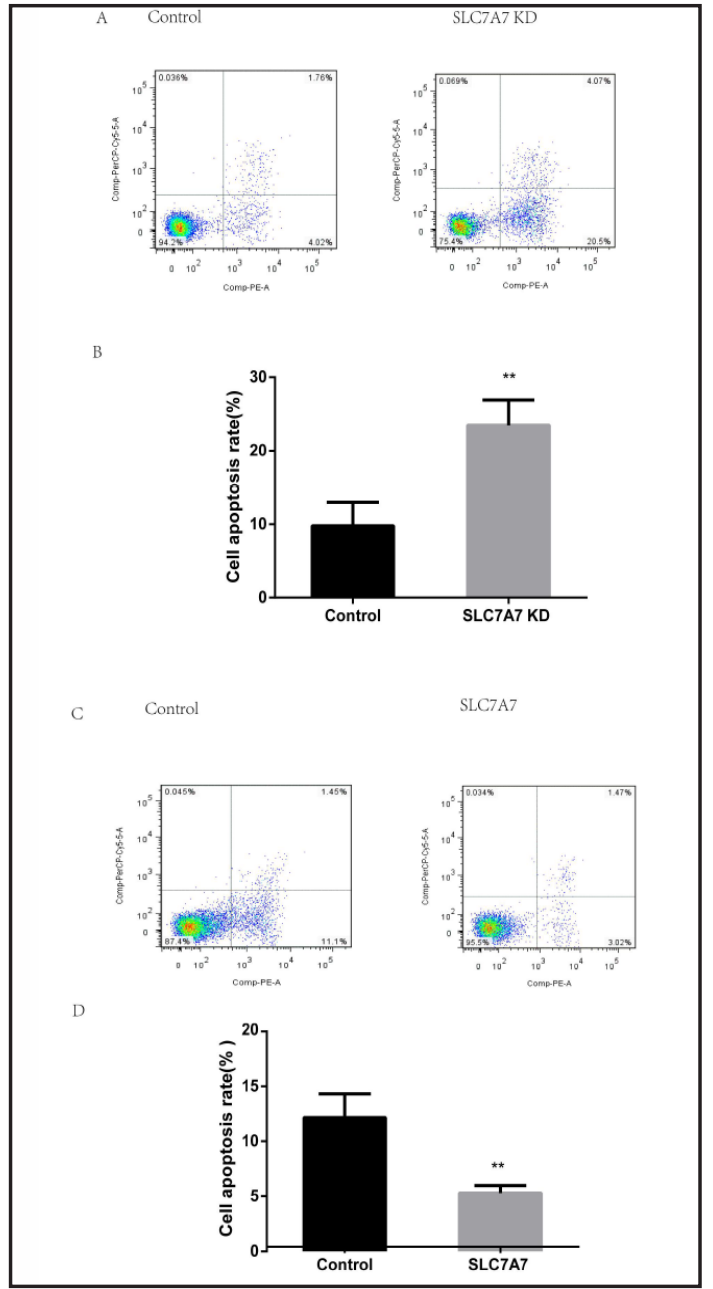

Fig. 4. Apoptosis rates of Jurkat cells exposed to different treatments. (A) Cell apoptosis rates in the control and Lv-shSLC7A7 groups. (B) Cell apoptosis rates in the control and Lv-shSLC7A7 groups. Compared with sh-NC-transfected cells, apoptosis was significantly increased in cells transfected with LvshSLC7A7 vector $(\mathrm{P}=0.007)$. (C) Cell apoptosis rates in the control and Lv-SLC7A7 groups. (D) Cell apoptosis rates in the control and Lv-SLC7A7 groups. Compared with the control group, apoptosis was decreased in cells transfected with the Lv-SLC7A7 vector $(\mathrm{P}=0.006)$.

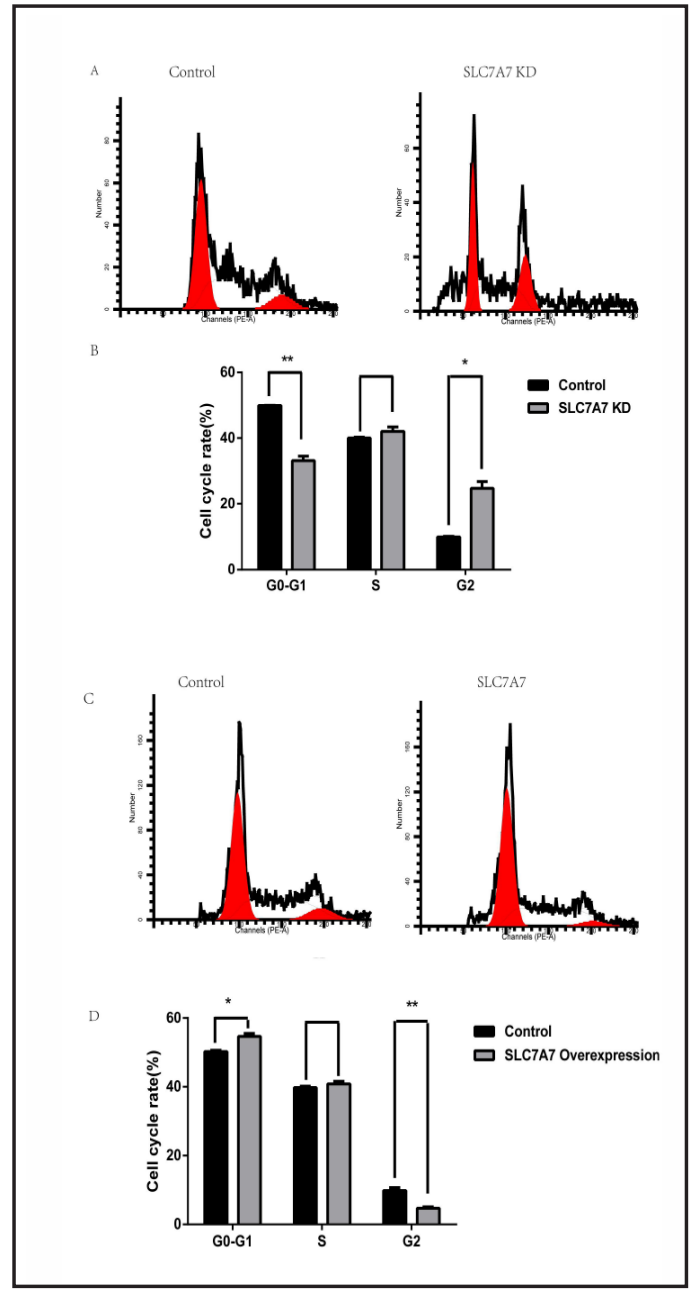

Fig. 5. Cell cycle of Jurkat cells exposed to different treatments. (A) The cell cycle in the control and Lv-shSLC7A7 groups. (B) The cell cycle in the control and Lv-shSLC7A7 groups. SLC7A7 knockdown dramatically decreased G1 phase cell numbers when compared with the negative control (NC) (P $=0.002)$. SLC7A7 knockdown increased G2 phase cell numbers $(\mathrm{P}=0.011)$. $(\mathrm{C})$ The cell cycle in the control and Lv-SLC7A7 groups. (D) The cycle in the control and Lv-SLC7A7 groups. Compared with the control group, overexpression of SLC7A7 promoted G1 phase cell numbers $(\mathrm{P}=0.029)$. Overexpression of SLC7A7 decreased G2 phase cell numbers ( $\mathrm{P}=$ 0.008). 


\section{Cellular Physiology Cell Physiol Biochem 2018;48:731-740 \begin{tabular}{l|l} 
DOI: 10.1159/000491899 & $\begin{array}{l}\text { O } 2018 \text { The Author(s). Published by S. Karger AG, Basel } \\
\text { www.karger.com/cpb }\end{array}$
\end{tabular} Ji et al.: Function of SLC7A7 in T-ALL}

Compared with sh-NC-transfected cells, the cell apoptosis rate was significantly increased in cells transfected with Lv-shSLC7A7 vector $(P=0.007$; Fig. 4B) but decreased in cells transfected with Lv-SLC7A7 vector ( $P=0.006$; Fig. 4D). Thus, we can conclude that SLC7A7 silencing induces cell apoptosis.

Compared with sh-NC-transfected cells, SLC7A7 knockdown dramatically decreased G1 phase cell numbers $(P=$ 0.002; Fig. 5B) and increased G2 phase cell numbers $(P=0.011$; Fig. 5B). Compared with the control group, overexpression of SLC7A7 promoted G1 phase cell numbers $(P=0.029$; Fig. 5D) and decreased G2 phase cell numbers $(P=0.008$; Fig. 5D). No significant difference was found in $\mathrm{S}$ cell numbers.

Effects of SLC7A7 on Jurkat cell migration and invasion

Cell migration and invasion assays confirmed that the migration ability of Jurkat cells was inhibited by transfection with the Lv-shSLC7A7 vector $(P<0.001$; Fig. 6B). In addition, the cell invasion ability of Jurkat cells was also inhibited by transfection with the Lv-shSLC7A7 vector $(P<0.001 ;$ Fig. 6B). In contrast, transfection with the Lv-SLC7A7 vector significantly increased cell migration $(P<0.001 ;$ Fig. 6D) and invasion $(P<0.001$; Fig. 6D).

Arginine content in the supernatant of transfected cells

The content of arginine in the supernatant of transfected cells was measured using a human arginine ELISA kit. We found that the supernatant content of arginine was increased in cells transfected with SLC7A7 overexpression vectors $(\mathrm{P}=$ 0.039; Fig. 7); the results were the opposite in SLC7A7-silenced cells $(\mathrm{P}=0.035)$.

\section{Discussion}

The proteins encoded by SLC7A7 are involved in formation of the cationic amino acid transport complex, which regulates the internal and external transport of amino acids. This system transports cationic

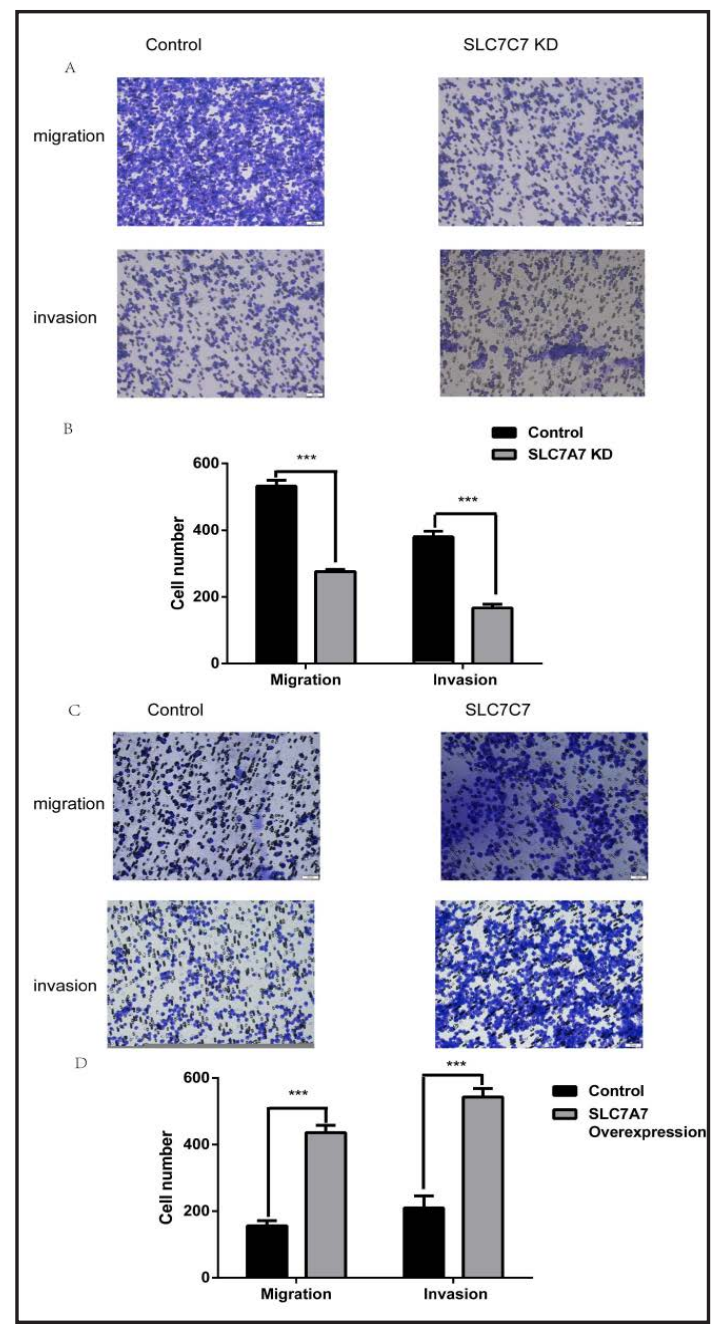

Fig. 6. Migration and invasion abilities of Jurkat cells exposed to different treatments. (A) Cell migration and invasion in the control and Lv-shSLC7A7 groups. (B) Compared with the control group, overexpression of SLC7A7 promoted cell migration $(\mathrm{P}<0.001)$ and invasion $(\mathrm{P}<0.001)$. (C) Migration and invasion in the control and Lv-SLC7A7 groups. (D) Compared with the control group, knockdown of SLC7A7 decreased cell migration $(\mathrm{P}<0.001)$ and invasion $(\mathrm{P}<0.001)$.

Fig. 7. Content of arginine in transfected cell supernatant as measured by an arginine ELISA

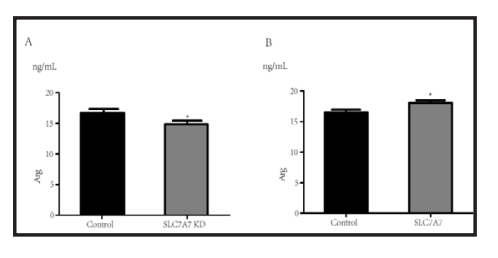
kit. (A) The supernatant content of arginine was decreased in cells transfected with SLC7A7 silencing vectors ( $\mathrm{P}=$ 0.035). (B) The results were the opposite in SLC7A7overexpressing cells $(\mathrm{P}=0.039)$. 
amino acids such as arginine and lysine out of the cell while allowing a large neutral amino acid and a $\mathrm{Na}^{+}$ion to enter the cell. Amino acids are essential to cell signaling pathways. For example, one of the cationic amino acids, arginine, is critical for T-cell activation and function in the immune response. L-arginine is a nonessential amino acid that plays a central role in regulating the immune response [19]. In the absence of L-arginine, T cells cannot be efficiently activated, proliferate, or produce cytokines [20]. Lower extracellular arginine in the microenvironment results in stagnation of T lymphocytes during the G0-G1 phase and leads to low T lymphocyte reactivity [21,22].

The pathogenesis and drug resistance of tumors are both associated with the abnormal expression of genes of the SLC superfamily, such as in liver cancer, colorectal cancer, and ovarian cancer [23-25]. Amino acid transporter proteins such as LAT1 affect the differentiation of T cells by regulating the activity of mTOR[22], and it has thus been used as a diagnostic and treatment target in prostate cancer [26]. Gene expression of SLC25A38, another member of the SLC superfamily, is significantly higher in ALL cell lines [27] and it may be a new biomarker for ALL diagnosis and treatment. SLC7A7 may also affect ALL cell function by regulating arginine transport. However, few studies have focused on the role of SLC7A7 in the development of ALL.

Our study found that SLC7A7 is overexpressed in patients with T-cell ALL versus controls. Data from another study also confirmed that SLC7A7 was upregulated at both mRNA and protein levels and that its overexpression was associated with poor prognosis in glioblastoma patients [28]. SLC7A7, involved in regulating amino acid transport, is closely linked to a variety of diseases [14-17]. A study focusing on ovarian cancers found that SLC7A7 may alter the influx/efflux of drugs from cells and thus modulate the chemotherapy response [16]. However, few studies have focused on the association between SLC7A7 and acute lymphocytic leukemia. In this study, we observed that SLC7A7 overexpression decreased the apoptosis rate, increased the proportion of cells in the G1 phase, decreased the proportion of G2 cells, and significantly increased cell migration and invasion.

As for the proliferative ability of Jurkat cells exposed to different treatments, we observed no clear changes among cells transfected with Lv-shSLC7A7 or Lv-SLC7A7 and their respective control groups after 3 days. Unlike normal cells and tissues, various tumor cells have long been known to be auxotrophic for arginine. At the same time, tumor cells will restore the auxotrophy by synthesizing arginine from alternative intermediates such as citrulline. In addition, supplementation of the medium with a plentiful supply of arginine generally overcomes this lack of arginine. The effect of arginine on different tumors varies due to the different types of tumor cells involved [29]. In our study, depletion of arginine did not significantly alter the proliferative ability of Jurkat cells. Knockdown of the SLC7A7 gene increased the apoptosis rate of Jurkat cells. The possible signaling pathway is as follows: depletion of SLC7A7 disables transport systems that transport cationic amino acids out of the cell, increasing the amount of intracellular cationic amino acids, which can activate MTOR and contribute to apoptosis [30,31]. mTOR activation initiates the mitochondrial pathway of apoptosis and leads to phosphorylation of its downstream effector 4E-BP. Phosphorylated $4 \mathrm{E}-\mathrm{BP}$ cannot bind eIF4E, leaving this translation factor free to upregulate the expression of proapoptotic proteins such as Bax [32]. It is possible that increased intracellular arginine would activate mTOR and induce apoptosis in SLC7A7 knockdown Jurkat cells. Our results also showed that knockdown of SLC7A7 gene expression can increase total mTOR protein levels (Fig. 8) and that overexpression of the SLC7A7 gene transports arginine out of the cell. Arginine starvation can result in G1 phase cell arrest $[21,22]$. Cells arrest at cell cycle

Fig. 8. Protein expression of mTOR in Jurkat cells exposed to different treatments. After transfection, the cells were treated with puromycin for 48 h. Protein expression of mTOR (western blot). (A) Protein expression of mTOR in the control and Lv-shSLC7A7 groups. (B) mTOR protein in the control and SLC7A7 overexpression groups.

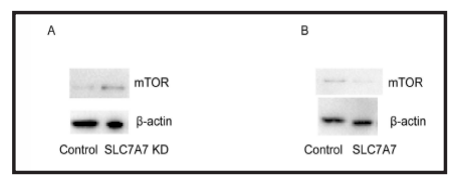




\section{Cellular Physiology Cell Physiol Biochem 2018;48:731-740 \begin{tabular}{c|c} 
DOI: 10.1159/000491899 & $\begin{array}{l}\text { O 2018 The Author(s). Published by S. Karger AG, Basel } \\
\text { www.karger.com/cpb }\end{array}$
\end{tabular} \\ Ji et al.: Function of SLC7A7 in T-ALL}

checkpoints for many reasons, such as to repair cellular damage or due to the availability of essential growth factors, hormones, or nutrients [33]. The G1/S checkpoint is responsible for resistance of tumor cells to chemotherapeutic agents or irradiation [34].

The CXCL12/CXCR4 signaling axis plays an important role in cancer cell migration and progression. L-arginine can decrease CXCR4 and CXCL12 mRNA levels in the cell to decrease cell migration and invasion [35]. This explains the decrease in cell migration and invasion after knockdown of SLC7A7 gene expression.

In addition, overexpression of the SLC7A7 gene leads to transport of arginine out of the cell and, in published studies, depletion of arginine resulted in G1 phase cell arrest $[21,22]$ and decreased cell proliferation. However, arginine has different effects on the proliferative ability of different tumor cells [29] and arginine depletion would increase cell migration and invasion ability [35] and decrease apoptosis [30]. In our research, the proliferative ability of Jurkat cells did not change but the proportion of G1 phase cells and migration and invasion ability increased and apoptosis decreased in SLC7A7-overexpressing cells. We also found that the expression of SLC7A7 was increased in T-ALL samples compared with controls. Additionally, we measured the supernatant content of arginine in transfected cells. We found that the supernatant content of arginine was increased in cells transfected with SLC7A7 overexpression vectors, with the opposite results seen in SLC7A7-silenced cells. Thus, we deduced that SLC7A7 affects cell functions by regulating the transport of arginine and that SLC7A7 is likely to facilitate the development of T-cell ALL. Although our study has found a relationship between SLC7A7 and Jurkat cells, the role of arginine in regulating cell function remains unknown and it is still unclear whether arginine is the link between SLC7A7 and cell function. More research on the role of arginine is required, which will open new avenues to explore the relationship among diseases, amino acids, and the amino acid transport system.

\section{Acknowledgements}

This study was supported by the National Natural Science Foundation of China under grant numbers 81602913, 81670155, and 81400116, the Natural Science Foundation of Jiangsu Province under grant number BK20150085, the Nanjing Medical Science and Technology Development Project under grant number YKK15140, the Nanjing Medical Science and Technology Development Foundation under grant number QRX17164, the Nanjing Science and Technology Development Foundation under grant number 201503043, and the Technology Development Foundation of Nanjing Medical University under grant numbers 2014NJMUZD0079 and 2014NJMU156.

\section{Disclosure Statement}

The authors declare to have no conflict of interests.

\section{References}

-1 Abboud MR, Ghanem K, Muwakkit S: Acute lymphoblastic leukemia in low and middle-income countries: disease characteristics and treatment results. Curr Opin Oncol 2014;26:650-655.

2 Winther JF SK: How safe is a standard-risk child with ALL. LANCET ONCOL 2014;15:782-783.

- 3 Locatelli F, Moretta F, Rutella S: Management of relapsed acute lymphoblastic leukemia in childhood with conventional and innovative approaches. Curr Opin Oncol 2013;25:707-715.

4 Hunger SP, Mullighan CG: Acute Lymphoblastic Leukemia in Children. N Engl J Med 2015;373:1541-1552.

5 Lu L, Wang F, He L, Xue Y, Wang Y, Zhang H, Rong L, Wang M, Zhang Z, Fang Y, Miao H: Interaction Between IGF1 Polymorphisms and the Risk of Acute Lymphoblastic Leukemia in Chinese Children. Cell Physiol Biochem 2015;36:1346-1358. 


\section{Cellular Physiology Cell Physiol Biochem 2018;48:731-740 \begin{tabular}{l|l} 
DOI: 10.1159/000491899 & Ond Biochemistry \\
Published online: July 19, 2018 & $\begin{array}{l}\text { 2018 The Author(s). Published by S. Karger AG, Basel } \\
\text { www.karger.com/cpb }\end{array}$ \\
\cline { 2 - 3 }
\end{tabular} \\ Ji et al.: Function of SLC7A7 in T-ALL}

6 Lin CM, Zeng YL, Xiao M, Mei XQ, Shen LY, Guo MX, Lin ZY, Liu QF, Yang T: The Relationship Between MMP-2 -1306C > T and MMP-9 -1562C>T Polymorphisms and the Risk and Prognosis of T-Cell Acute Lymphoblastic Leukemia in a Chinese Population: A Case-Control Study. Cell Physiol Biochem 2017;42:1458-1468.

7 ABAC PF: Amino acid regulation of gene expression. BIOCHEM J 2000;351:1-12.

8 He L, Vasiliou K, Nebert DW: Analysis and update of the human solute carrier (SLC) gene superfamily. Hum Genomics 2009;3:195-206.

-9 Cedernaes J, Olszewski PK, Almen MS, Stephansson O, Levine AS, Fredriksson R, Nylander O, Schioth HB: Comprehensive analysis of localization of 78 solute carrier genes throughout the subsections of the rat gastrointestinal tract. Biochem Biophys Res Commun 2011;411:702-707.

10 Broer S, Palacin M: The role of amino acid transporters in inherited and acquired diseases. Biochem J 2011;436:193-211.

11 Broer A, Wagner CA, Lang F, Broer S: The heterodimeric amino acid transporter 4F2hc/y+LAT2 mediates arginine efflux in exchange with glutamine. Biochem J 2000;349 Pt 3:787-795.

12 Kanai Y, Fukasawa Y, Cha SH, Segawa H, Chairoungdua A, Kim DK, Matsuo H, Kim JY, Miyamoto K, Takeda E, Endou H: Transport properties of a system $y+L$ neutral and basic amino acid transporter. Insights into the mechanisms of substrate recognition. J Biol Chem 2000;275:20787-20793.

13 Sperandeo MP, Andria G, Sebastio G: Lysinuric protein intolerance: update and extended mutation analysis of the SLC7A7 gene. Hum Mutat 2008;29:14-21.

14 Fan S, Zhao Y, Li X, Du Y, Wang J, Song X, Zhou F, Chen H, Chen G, Zhao Y, Mao Y, Lan Q: Genetic variants in SLC7A7 are associated with risk of glioma in a Chinese population. Exp Biol Med (Maywood) 2013;238:1075-1081.

15 Agnelli L, Forcato M, Ferrari F, Tuana G, Todoerti K, Walker BA, Morgan GJ, Lombardi L, Bicciato S, Neri A: The reconstruction of transcriptional networks reveals critical genes with implications for clinical outcome of multiple myeloma. Clin Cancer Res 2011;17:7402-7412.

16 Cheng L, Lu W, Kulkarni B, Pejovic T, Yan X, Chiang JH, Hood L, Odunsi K, Lin B: Analysis of chemotherapy response programs in ovarian cancers by the next-generation sequencing technologies. Gynecol Oncol 2010;117:159-169.

17 Xie L, Song X, Yu J, Guo W, Wei L, Liu Y, Wang X: Solute carrier protein family may involve in radiationinduced radioresistance of non-small cell lung cancer. J Cancer Res Clin Oncol 2011;137:1739-1747.

18 Barilli A, Rotoli BM, Visigalli R, Bussolati O, Gazzola GC, Dall'Asta V: Arginine transport in human monocytic leukemia THP-1 cells during macrophage differentiation. J Leukoc Biol 2011;90:293-303.

19 Bronte V, Zanovello P: Regulation of immune responses by L-arginine metabolism. Nat Rev Immunol 2005;5:641-654.

20 Choi BS, Martinez-Falero IC, Corset C, Munder M, Modolell M, Muller I, Kropf P: Differential impact of L-arginine deprivation on the activation and effector functions of $\mathrm{T}$ cells and macrophages. J Leukoc Biol 2009;85:268-277.

21 Rodriguez PC QD, Ochoa AC: L-arginine availability regulatesT-lymphocyte cell-cycle progression. Blofigod 2007;109:1568-1573.

-22 GLJY WR: Amino-acid transporters in T-cell activation and differentiation. . Cell Death and Disease 2017;8:e2757.

23 Jong NN, McKeage MJ: Emerging roles of metal solute carriers in cancer mechanisms and treatment. Biopharm Drug Dispos 2014;35:450-462.

24 Haussinger D, Kubitz R, Reinehr R, Bode JG, Schliess F: Molecular aspects of medicine: from experimental to clinical hepatology. Mol Aspects Med 2004;25:221-360.

25 Sprowl JA, Mikkelsen TS, Giovinazzo H, Sparreboom A: Contribution of tumoral and host solute carriers to clinical drug response. Drug Resist Updat 2012;15:5-20.

-26 Jin SE, Jin HE, Hong SS: Targeting L-type amino acid transporter 1 for anticancer therapy: clinical impact from diagnostics to therapeutics. Expert Opin Ther Targets 2015;19:1319-1337.

27 Chen H, Lu Q, Zhang Y, Zhang C, Zhang H, Xu H: Overexpression of SLC25A38 protein on acute lymphoblastic leukemia cells. Oncol Lett 2014;7:1422-1426.

28 Fan S, Meng D, Xu T, Chen Y, Wang J, Li X, Chen H, Lu D, Chen J, Lan Q: Overexpression of SLC7A7 predicts poor progression-free and overall survival in patients with glioblastoma. Med Oncol 2013;30:384. 


\section{Cellular Physiology Cell Physiol Biochem 2018:48:731-740 \begin{tabular}{l|l} 
DOI: 10.1159/000491899 & $\begin{array}{l}\text { O 2018 The Author(s). Published by S. Karger AG, Basel } \\
\text { www.karger.com/cpb }\end{array}$ \\
\hline
\end{tabular} \\ Ji et al.: Function of SLC7A7 in T-ALL}

29 Dillon BJ, Prieto VG, Curley SA, Ensor CM, Holtsberg FW, Bomalaski JS, Clark MA: Incidence and distribution of argininosuccinate synthetase deficiency in human cancers: a method for identifying cancers sensitive to arginine deprivation. Cancer 2004;100:826-833.

-30 Laplante M, Sabatini DM: mTOR signaling in growth control and disease. Cell 2012;149:274-293.

-31 Han J, Lin M, Zhou D, Zhang Z, Jin R, Zhou F: Huang Qi Huai Granules Induce Apoptosis in Acute Lymphoblastic Leukemia Cells through the Akt/Fox01 Pathway. Cellular Physiology and Biochemistry 2016;38:1803-1814.

-32 Nikoletopoulou V, Markaki M, Palikaras K, Tavernarakis N: Crosstalk between apoptosis, necrosis and autophagy. Biochim Biophys Acta 2013;1833:3448-3459.

-33 ZAS: JAP: Cell cycle checkpoint signaling: Cell cycle arrest versus apoptosis. . TOXICOLOGY 2002;181182:475-481.

34 M: M: Cell cycle checkpoints and their inactivation in human cancer. Cell Prolif 2000;33:261-274.

-35 Jahani M, Azadbakht M, Norooznezhad F, Mansouri K: l-arginine alters the effect of 5-fluorouracil on breast cancer cells in favor of apoptosis. Biomed Pharmacother 2017;88:114-123. 